\title{
ARTESUNATE LOADED NANOFIBER AND ITS COMBINATIONS WITH SPIRAMYCIN FOR TREATMENT OF MURINE TOXOPLASMOSIS
}

\author{
By
}

ENAS F. ABDEL HAMED ${ }^{1 *}$, NAHED E. MOSTAFA ${ }^{1}$, AMIRA A. SALEH ${ }^{1}$, MARWA A. SALAMA ${ }^{1}$, SHEREEN M. IBRAHIM ${ }^{1}$, SAID M. AHMED ${ }^{2}$, And HAYAM E. RASHED ${ }^{3}$

Department of Medical Parasitology ${ }^{1}$, Faculty of Medicine, Department of Zoology ${ }^{2}$, Faculty of Science, and Department of Pathology ${ }^{3}$, Faculty of Medicine, Zagazig University, Zagazig, Egypt

( ${ }^{*}$ Correspondence: enas_refae1983@yahoo.com) Phone: +20 01143366064

ORCID ID:0000-0002-4039-2710

\section{Abstract}

Although toxoplasmosis is worldwide spread, the available medications have low efficacy and high toxicity. This research aims to study the effect of artesunate loaded nanofiber and its combination with spiramycin as an alternative treatment for murine toxoplasmosis. Two groups of male Swiss albino male mice were used for acute and chronic phases of Toxoplasma infection. Mice were infected with 100 viable tachyzoites of RH type-1 virulent strain intraperitoneally and orally with 100 viable tissue cysts of ME 49 Toxoplasma strain. They were orally treated with the drugs. The doses of the drug were administered from the first to the fifth day post-infection in acute infection and after six weeks in chronic one. Tachyzoites in peritoneum and cysts burden in the brain were subjected for parasitological analysis, Histopathological study and ultrastructural study by Scanning Electron microscopy (SEM). Liver enzymes analysis was done for biochemical assessment drugs. The combination artesunate loaded nanofiber and spiramycin gave the least number of tachyzoites (139) and brain tissue cysts (125) with the highest percentage reductions $(85 \%, 84.3 \%)$ consequently. SEM revealed a reduction in the size of tachyzoites with surface irregularity and abnormal protrusions in the treated group with the drug combination. Brain tissue cyst of the same group showed a distortion in the shape and size with patches all over the surface.

Key words: Toxoplasmosis, Artesunate loaded nanofiber, Spiramycin

\section{Introduction}

Toxoplasma gondii is an obligate intracellular protozoan (Robert-Gangneux and Dardé, 2012), transmitted orally, congenital and blood transfusion (Scallan et al, 2011). Almost, $30 \%$ of world's population has antibodies to Toxoplasma gondii (Wang et al, 2017). Acute toxoplasmosis caused by tachyzoites developed to tissue cysts containing bradyzoites (Pappas et al, 2009) which represent the latent infection that can be reactivated if the immune system is impaired, causing fatal cerebral toxoplasmosis (Weiss and Kim 2014). Pyrimethamine and sulfadiazine combination is the most effective treatment for toxoplasmosis, with some significant side effects, including bone marrow suppression, hypersensitivity, and teratogenic effects (Peters, 2007). They eliminated $T$. gondii tachyzoites but not bradyzoites besides, their high toxicity and severe adverse

\section{effects (McLeod et al, 2014).}

Artemisinin is a herbal extract of Artemisia annua having antimalarial activity and low toxicity in animals and humans (Mesa et $a l, 2015)$. Artesunate and artemether are the only 2 derivatives of artemisinin that have been certified since 1990. Artesunate contains an endopero-xide bridge causing peroxide moiety that is responsible for the antimalaria activity (Barradell and Fitton, 1995) and the anti-Toxoplasma activity (Ou-Yang et al, 1990). Spiramycin is a macrolide antibiotic which is used safely against $T$. gondii in pregnancy (Engel et al, 2000) and compared the effect of this safe drug with the target combination.

Electrospinning is a simple method of electrospun nanofiber scaffolds production (Ramakrishna et al, 2005). Different type of natural polymers such as Polyethylene oxide (PEO) was used to fabricate Electrospun 
scaffolds (Ma et al, 2011). Electrospun nanofibers are biodegradable polymers; which is very crucial in drug delivery. Due to PEO excellent biocompatibility, safety, and solubility in water or other solvents, it is widely used for drug carriers; internal food applications, pharmaceutical, and other human care products (Shenoy et al, 2005).

The study aimed to evaluate synergistic effect of these polymers after combining the artesunate drug to electrospinning on both tachyzoites and bradyzoites.

\section{Material and Methods}

Ethical Statement and Recruitment: The study was approved by the Research Ethics Committee, Faculty of Medicine, Zagazig University. The experimental studies were conducted in accordance with international valid guidelines and they were maintained under convenient conditions at SBSP animal house of TBRI.

Toxoplasma gondii RH strain (Type 1, virulent strain) and Toxoplasma gondii $\mathrm{M} \mathrm{E}$ 49 strain were maintained in laborato-ry, Department of Parasitology (TBRI), Egypt. For animal's infection, tachyzoites were harvested from peritoneal exudates of infected mice at the fourth day of infection; debris and host cells were removed and filtrated through a sheet of glass wool fibers. The filtrate was washed three times and diluted with phosphate buffer saline (PBS) PH 7.4. About 100 active tachyzoites/male Swiss Albino mice were injected intraperitoneal for acute infection. The ME49 chronic strain was obtained from the homogenized brain of infected mice and diluted with PBS PH 7.4. 100 tissue cyst/ male mice were infected orally (Daryani et al, 2003).

Nanopolymer For $8 \mathrm{hrs}$, polyethylene oxide (PEO, Mv, 900,000, Sigma, Aldrich) and Artesunate (Artesunatum) drug were dissolved in MilliQ water to prepare polymer solutions (Tamer and Flemming, 2009). Four different pure PEO concentrations (3\%, 7\%, $9 \% \& 11 \% \mathrm{w} / \mathrm{v})$ were prepared. With respect to PEO final concentration, $10 \% \mathrm{w} / \mathrm{w}$ of drug concentrations was used. A $5 \mathrm{ml}$ syringe with a stainless steel needle 27 was loaded with a mixture of PEO \& PEO/Artesunate solutions individually. The solutions were electrospun by using a standard high voltage power supply (Spellman High Voltage Elec. Corp., M $\mathrm{P}$ series), after placing the loaded syringes horizontally on the syringe pump (Model: KDS 101, KD Scientific). Process of electrospinning was performed using a feed rate of $0.5 \mathrm{~mm} / \mathrm{min}$, an applied voltage of $17 \mathrm{kv}$ and collector distance of $20 \mathrm{~cm}$. For nanofiber scaffolds deposition, a piece of aluminum foil was used to cover the grounded stationary rectangular metal collector.

Fabrication of PEO \& PEO loaded with Artesunate nanofibers by electrospinning nanofiber fabrication was prepared by an electrospinning workstation (Ucalery, Beijing, China SS-25344, UC120815). A 10-mL NormectLuerL of plastic syringe with 27 gauge stainless-steel needles was used to load the spinning solutions. To collect nanofibers, a laboratory-produced roller that covered with aluminum foil was used. Du-ring the process of electrospinning, the needle tip, flow rate, applied voltage and the distance of the needle tip to the collector were monitored and kept at $0.27 \mathrm{~mm}, 0.5 \mathrm{~mm} / \mathrm{min}, 17 \mathrm{kv}, \& 20 \mathrm{~cm}$ respectively all the time. To clean solvent residues, nanofibers were removed and collected from the aluminum foil kept in the vacuum at room temperature for $4 \mathrm{hrs}$ then placed to dry for several days.

Characterization of electrospunnanofibers: A field emission SEM (FE-SEM S-4800, Hitachi Ltd., Japan) was utilized to examine the morphology of the prepared nanofibers using accelerating voltage of $10 \mathrm{Kv}$ (Fig.1). For SEM observation, the specimens were covered with an aluminum sheet lined with the as-spun product sand. Each examined sections was fixed on a copper stub and coated with gold by a Balzers Union SCD 040 sputtering device. Image-Pro plus 6.0 (Media Cybernetics, Inc., USA) was used to examine fiber diameters. For accuracy, the averages of 30 fibers were measured and standard deviations were used for descrip- 
tive error bars. Solution with high molecular weight was used for electrospinning to produce optimum electrospun PEO nanofibres. Desired concentration of PEO was obtained by dissolving polyethylene oxide (PEO) dissolved in water by different concentrations and used to facilitate PEO morphology examination using FE-SEM images (Tamer and Flemming, 2009).

All drugs used were given at the first day of infection. Spiramycin (PHRAONIA Pharmaceuticals 1.500000 ) was orally given in a dose of $200 \mathrm{mg} / \mathrm{kg}$ daily for 5days in acute infection groups and after 6 weeks in chronic groups. For adjusting the dose of Artusenate and Artesunate loaded nanofiber, a pilot study was done. Artusenate was given in dose plans of $150,180,200,250 \mathrm{mg} / \mathrm{kg} / \mathrm{day}$ for 5 days, while artesunate loaded nanofiber was given in dose of $100,130,150 \& 200$ $\mathrm{mg} / \mathrm{kg} /$ day for 5 days. Artesunate (Ipca Laboratories, Sejvta, Ratlam, Kandivliind. Estate) was given in a dose of $200 \mathrm{mg} / \mathrm{kg}$ body weight/ day for 5 days. Nano-drug was given at a dose of $130 \mathrm{mg} / \mathrm{kg}$ body weight/day. Half dose of spiramycin $(100 \mathrm{mg} / \mathrm{kg})$ \& Artesunate loaded nanofibers $(65 \mathrm{mg} / \mathrm{kg})$ were given daily as combined therapy (VI \& VII).

Experimental design: One hundred and forty male Swiss Albino mice aged 6-7 weeks old, weight 20-22gm obtained from Schistosome Biological Supply Program, Theodor Bilharz Research Institute Cairo. Animals were divided into two groups. The first one was group of acute infection (a) divided into 7 subgroups of 5 mouse each: $\mathrm{G1}^{\mathrm{a}}$ : control uninfected, $\mathrm{G}^{\mathrm{a}}$ : control infected, $\mathrm{G} 3^{\mathrm{a}}$ : infected and treated with spiramycin, $\mathrm{G} 4^{\mathrm{a}}$ : infected and treated with artesunate, $\mathrm{G}^{\mathrm{a}}$ : infected and treated with artesunate-loaded nanofiber, G6 ${ }^{\mathrm{a}}$ : infected and treated with combination of artesunate $\&$ spiramycin, $G 7^{\mathrm{a}}$ : infected and treated with the target combination of artesunate loaded nanofiber \& spiramycin. The second one was the chronic infection group (b) consists of seven subgroups of 5 mouse each: $\mathrm{G} 1^{\mathrm{b}}$ : control uninfected, $\mathrm{G} 2^{\mathrm{b}}$ : control infected, $\mathrm{G} 3^{\mathrm{b}}$ : infected and tre- ated with spiramycin, $\mathrm{G} 4^{\mathrm{b}}$ : infected and treated with artesunate, $\mathrm{G} 5^{\mathrm{b}}$ : infected and treated with artesunate-loaded nanofiber, $\mathrm{G}^{\mathrm{b}}$ : infected and treated with combination of artesunate \& spiramycin, $\mathrm{G}^{\mathrm{b}}$ : infected and treated with target combination of artesunate loaded nanofiber \& spiramycin. Mice were sacrificed 5 days post infection for group ${ }^{a}$ and 8 weeks post infection for group ${ }^{\mathrm{b}}$. Infection assessment and drug effect was evaluated parasitological, histopathological, ultra structural study and by liver function tests.

Parasitological study: A- Acute phase: on $5^{\text {th }}$ day post infection, peritoneal fluid with T. gondii tachyzoites were collected from infected groups to count tachyzoites by hemocytometer per mouse, in 10 high power field (HPF), mean number of tachyzoites/10 HPF was considered. Morphological features of tachyzoites were examined by light microscopy \& SEM. B- Chronic phase: on $8^{\text {th }}$ week post infect-ion, brain with tissue cysts was obtained from each group, homogenized, stained by Gimsa stain, and examined by light microscope to count number of tissue cysts, mean of 10 fields was calculated (Barakat, 2007). Reduction percent $(\% \mathrm{R})$ in parasite were calculated (Penido et al, 1994) using equation: $\% \mathrm{R}=100(\mathrm{C}-\mathrm{E} / \mathrm{C})$; $\mathrm{C}$ : control subgroups, $\mathrm{E}$ : experimental mice groups.

SEM study was done for peritoneal tachyzoites and brain tissue cysts of infected treated mice compared to infected non-treated ones (González-del et al, 2009).

Liver function tests: AST \& ALT were measured for infected groups as compared to non-infected non-treated control ones spectrophotometric by an automatic analyzer.

Statistical analysis; Data were analyzed using SPSS 18 program. Quantitative data were expressed as $\mathrm{M} \pm \mathrm{SD}$. ANOVA was used to find difference between different groups (least significant difference) test was used to find differences between groups Pvalue $>0.05$ indicated non-significant, $<0.05$ significant and P-value $<0.01$ was highly significant (Kirkwood, 2003). 
Results

Table 1: Therapeutic effect of Artesunate loaded nanofibers and its combination with spiramycin during tacute and chronic Toxoplasma infection.

\begin{tabular}{|c|c|c|c|c|c|c|c|}
\hline \multirow{3}{*}{$\begin{array}{l}\text { Variable } \\
\text { Tachyzo- } \\
\text { ite }\end{array}$} & \multirow{2}{*}{\begin{tabular}{|l|} 
Group \\
Control normal(G1)
\end{tabular}} & \multirow{2}{*}{ Mean } & \multirow{2}{*}{ SD } & \multicolumn{2}{|c|}{ Range } & \multirow[t]{2}{*}{$\mathrm{F}$} & \multirow[t]{2}{*}{$\mathrm{P}$} \\
\hline & & & & . & . & & \\
\hline & Control infected (G2) & $926.80^{\# \#}$ & 105.84 & 792 & 1078 & & \\
\hline & Spiramycin (G3) & $707.60^{*}$,\#\# & 26.65 & 678 & 750 & & \\
\hline & Artesunate (G4) & $630.00^{* *, \# \#}$ & 77.39 & 506 & 704 & 206.53 & $<0.001 \mathrm{HS}$ \\
\hline & Artesunate loaded nano (G5) & $467.40^{* *, \# \#}$ & 32.04 & 418 & 500 & & \\
\hline & Artesunate+Spiramycin (G6) & $354.80^{* *, \# \#}$ & 33.88 & 308 & 396 & & \\
\hline & Artesunate loaded nano+ Spiramycin (G7) & $139.00^{\text {** }}$ & 48.58 & 95 & 200 & & \\
\hline \multirow{7}{*}{$\begin{array}{l}\text { Tissue } \\
\text { Cyst }\end{array}$} & Control normal(G1) & . & . & . & . & & \\
\hline & Control infected (G2) & $1500.6^{\# \#}$ & 355.31 & 1020 & 1999 & & \\
\hline & Spiramycin (G3) & $938.00^{* *, \# \#}$ & 117.08 & 800 & 1120 & & \\
\hline & Artesunate (G4) & $762.00^{* *, \# \#}$ & 72.54 & 680 & 870 & 50.01 & $<0.001 \mathrm{HS}$ \\
\hline & Artesunate loaded nano (G5) & $668.00^{* *, \# \#}$ & 244.62 & 380 & 1020 & & \\
\hline & Artesunate+Spiramycin (G6) & $595.60^{* *, \# \#}$ & 69.52 & 500 & 688 & & \\
\hline & Artesunate loaded nano+ Spiramycin (G7) & $235.00^{* *}$ & 56.86 & 187 & 330 & & \\
\hline
\end{tabular}

HS: Highly significant $(\mathrm{P}<0.01)$, *Significant with G2, **Highly significant with G2, \#Significant with G7, \#\#:Highly Significant with G7

Table 2: Percentage reduction of tachyzoites and tissue cysts in studied groups.

\begin{tabular}{|l|l|l|l|l|}
\hline Variable & \multicolumn{1}{|c|}{ Group } & Reduction\% & F & P \\
\hline Tachyzoite & Control normal(G1) & & \\
\cline { 2 - 5 } & Control infected (G2) & & & \\
\cline { 2 - 5 } & Spiramycin (G3) & $23.6 \%$ & & \\
\cline { 2 - 5 } & Artesunate (G4) & $32 \%$ & & \\
\cline { 2 - 5 } & Artesunate loaded nano (G5) & $49.5 \%$ & 79.39 & $<0.001$ \\
\cline { 2 - 5 } & Artesunate+Spiramycin (G6) & $61.7 \%$ & & \\
\cline { 2 - 5 } & Artesunate loaded nano+ Spiramycin (G7) & $85 \%$ & & \\
\hline \multirow{5}{*}{ Tissue Cyst } & Control normal(G1) & & & \\
\cline { 2 - 5 } & Control infected (G2) & $37.4 \%$ & & \\
\cline { 2 - 5 } & Spiramycin (G3) & $49.2 \%$ & & \\
\cline { 2 - 5 } & Artesunate (G4) & $55.4 \%$ & & \\
\cline { 2 - 5 } & Artesunate loaded nano (G5) & $60.3 \%$ & & \\
\cline { 2 - 5 } & Artesunate+Spiramycin (G6) & & \\
\cline { 2 - 5 } & Artesunate loaded nano+ Spiramycin (G7) & $84.3 \%$ & & \\
\hline
\end{tabular}

\section{Discussion}

Although the combination of pyrimethamine and sulfadiazine was the main treatment for T. gondii (Martins-Duarte et al, 2013) dangerous side effects existed, as hematological toxicity to pyrimethamine and /or hypersensitivity to sulfadiazine (Meneceur et al, 2008). Spiramycin was used alone or combined with sulfadiazine and pyrimethamine but produced toxic effects (Antczak $e t$ $a l, 2016)$. These side effects disrupt infection cure led to relapse after treatment cessation and accessible drugs have no effect on chronic stage (Martins-Duarte et al, 2010).

Artemisinin (ART) \& its derivatives were considered as the antimalarial, anti-schistos- omal agent, and effective against $T$. gondii (Holfels et al, 1994) and a wide range of protozoan (Loo et al, 2017). ART supported apoptosis of infected host cells and inhibited inflammatory response (Jiao et al, 2018).

Individual nanofibers and nanofibrous scaffolds served as attractive vehicles for delivery of therapeutic agents. Large surface area and microporous structure of nanofiber networks have advantageous for encapsulation and direct incorporation of active biomolecules, including drugs, into nanofibers for cellular function modulation, which nanoibers as a carrier for therapeutic agent delivery (Kenry and Chweem, 2017). 
Table 3: Activity of aspartate aminotransferase and alanine transaminase in serum of studied groups

\begin{tabular}{|c|c|c|c|c|c|c|c|}
\hline Variable & Group & Mean & $\mathrm{SD}$ & \multicolumn{2}{|c|}{ Range } & $\mathrm{F}$ & $\mathrm{P}$ \\
\hline \multirow{7}{*}{$\begin{array}{l}\text { AST } \\
\text { Acute stage }\end{array}$} & Control normal(G1) & $96.60^{* *}, \# \#$ & 11.27 & 80. & 110 & & \\
\hline & Control infected (G2) & $1817.40^{\# \#}$ & 268.10 & 1500 & 2200 & & \\
\hline & Spiramycin (G3) & $1190.0^{* *, \# \#}$ & 322.06 & 921 & 1765 & & \\
\hline & Artesunate $(\mathrm{G} 4)$ & $918.80^{* *}, \# \#$ & 67.39 & 832 & 998 & 127.56 & $<0.001 \mathrm{HS}$ \\
\hline & Artesunate loaded nano (G5) & $710.40^{* *}, \#$ & 29.29 & 687 & 765 & & \\
\hline & Artesunate+Spiramycin (G6) & $576.00^{* *}, \#$ & 38.64 & 504 & 604 & & \\
\hline & Artesunate loaded nano+ Spiramycin (G7) & $281.00^{* *}$ & 49.63 & 207 & 345 & & \\
\hline \multirow{7}{*}{$\begin{array}{l}\text { ALT } \\
\text { Acute stage }\end{array}$} & Control normal(G1) & $24.80^{* *, \#}$ & 8.93 & 15 & 38 & & \\
\hline & Control infected (G2) & $159.00^{\# \#}$ & 32.04 & 120 & 210 & & \\
\hline & Spiramycin (G3) & $152.00 * . \#$ & 32.93 & 110 & 200 & 73.97 & $<0.001 \mathrm{HS}$ \\
\hline & Artesunate (G4) & $124.00^{* *, \# \#}$ & 21.71 & 100 & 150 & & \\
\hline & Artesunate loaded nano (G5) & $89.40^{* *, \# \#}$ & 7.35 & 80 & 100 & & \\
\hline & Artesunate+Spiramycin (G6) & $77.00^{* *}, \# \#$ & 5.08 & 70 & 84 & & \\
\hline & Artesunate loaded nano+ Spiramycin (G7) & $29.40^{* *}$ & 7.71 & 17 & 40 & & \\
\hline \multirow{7}{*}{$\begin{array}{l}\text { ALT Chroinc } \\
\text { stage }\end{array}$} & Control normal $(\mathrm{G} 1)$ & $24.80^{* *}$ & 8.93 & 15 & 38 & & \\
\hline & Control infected (G2) & $98.20^{\# \#}$ & 23.07 & 80 & 140 & & \\
\hline & Spiramycin (G3) & $87.40^{*}, \# \#$ & 12.78 & 77 & 110 & 53.07 & $<0.001 \mathrm{HS}$ \\
\hline & Artesunate (G4) & $80.00^{*}, \# \#$ & 11.55 & 70 & 100 & & \\
\hline & Artesunate loaded nano (G5) & $74.80^{* *, \# \#}$ & 10.65 & 60 & 90 & & \\
\hline & Artesunate+Spiramycin (G6) & $56.20^{* * * \# \#}$ & 8.21 & 47 & 69 & & \\
\hline & Artesunate loaded nano+ Spiramycin (G7) & $25.00^{* * *}$ & 7.45 & 15 & 35 & & \\
\hline \multirow{7}{*}{$\begin{array}{l}\text { AST Chroinc } \\
\text { stage }\end{array}$} & Control normal(G1) & $96.60 * *$ & 11.27 & 80 & 110 & & \\
\hline & Control infected (G2) & $712.00^{\# \#}$ & 74.03 & 632 & 800 & & \\
\hline & Spiramycin (G3) & 680.20 *\#\# & 67.27 & 600 & 779 & 291.26 & $<0.001 \mathrm{HS}$ \\
\hline & Artesunate (G4) & $620.00^{*, \# \#}$ & 46.67 & 570 & 700 & & \\
\hline & Artesunate loaded nano (G5) & $544.20^{* * * \# \#}$ & 44.01 & 500 & 600 & & \\
\hline & Artesunate+Spiramycin (G6) & $421.00^{* *, \# \#}$ & 42.22 & 390 & 500 & & \\
\hline & Artesunate loaded nano+ Spiramycin (G7) & $99.40^{* *}$ & 17.66 & 80 & 130 & & \\
\hline
\end{tabular}

*Significant with G2, **: Highly Significant with G2, \#: Significant with G7, \#\#:Highly Significant with G7

A wide range of polymers was used to fabricate Electrospun scaffolds. Natural polymers are collagen, chitosan, gelatin, hyaluronic acid, and well-known synthetic polymers like polylactic acid (PLA), polycaprolactone (PCL), polyethylene oxide (PEO) and other similar copolymers (Seeram et al, 2013). These polymers characterized by biocompatibility and biodegradability (Chan $e t$ $a l, 2010)$, have a direct effect on pathogens and to the guidance of drugs to target (mainly intracellular pathogens). They improve bioavailability and stability, control the drug release, enhance its activity, avoid its degradation and decrease its toxicity (Gutiérrez et al, 2016; Khalil et al, 2013). Electrospun polymeric nanofibers released a new era in drug delivery system, as drug/drug nanoparticle loaded nanofibers were involved in treatment of diseases related to brain, eye, ear, cardiovascular system, lungs and oral cavity (Thakkar and Misra, 2017).

In the present study, the efficacy of artesunate loaded nanofiber and its combination with spiramycin were evaluated for treatment of acute and chronic phase of toxoplasmosis. El-Temsahy et al. (2002) confirmed that assessment of parasite density can determine the load of infection.

In the present study, in acute toxoplasmosis tachyzoites mean number decreased in treated groups (G3, G4, G5, G6) (707. 60, $630.00,467.40,354.80)$ respectively. Spiramycin had a synergistic effect when combi- 
ned with artesunate in G6 where reduction was $61.7 \%$ \& $60.3 \%$ in numbers of tachyzoites \& cysts respectively. Lowest tachyzoites mean number (139) and highest reduction $(85 \%)$ were in $(\mathrm{G} 7)$ treated with novel combination with high significance $(\mathrm{P}<0.001)$. This agreed with Gomes et al. (2012) who found that artesunate had an anti-toxoplasmosis effect \& Abou-El-Naga et al. (2017) who reported that polylacticcoglycolic acid (PLGA) nanoparticles improved the lopinavir/ritonavir effect in acute Toxoplasma infection. El-Zawawy et al. (2015b) found that triclosan and triclosan-loaded liposomal nanoparticles caused a significant decrease in the mean number of tachyzoites in peritoneal fluid of infected-treated groups reducing tachyzoites number. The highly significant difference in the present results might be due to different drugs, nanoparticles used, and dosage as well. During chronic stage, mean number of brain cyst was gradually decreased in treated groups (G3, G4, G5, \& G6) $(938,762,668,595)$. Lowest brain tissue cyst burden was in G7 with a mean value of 235 and highest reduction $(84.3 \%)$ were in the group treated with novel combination, with a very high significance value $(\mathrm{P}<0.001)$. This agreed with El-Zawawy et al. (2015a) who reported that mice treatment with triclosan (TS) and TS-liposomal decreased infection to $70 \%$. This dissimilarity might due to different drug loaded on nanoparticles. Shubar et al. (2011) found that oral treatment with atovaquone nanosuspension (ASN) combined with sodium dodecyl sulfate (SDS) reduced inflammation, parasite number \& DNA concentration in animals' brains.

The present histological study, target mice treated with drug combination showed increased astrocytes, neurons, and gliosis when compared with infected control and treated groups. Ultrastructure study revealed a reduction in tachyzoites size with an irregularity in surface and abnormal protrusions. Besides, brain tissue cyst of this group showed a distortion in shape and size and presence of patches all over, when compared with the infected non-treated group. This might be the first SEM study on the effect of artesunate loaded nanofibers on $T$. gondii tachyzoites and brain tissue cysts. El Zawawy (2008) by SEM reported a distortion in tachyzoites shape and erosions in mice treated with artesunate. The present result agreed with El-Zawawy et al. (2015b) who reported similar changes in Toxoplasma tachyzoites in mice treated with TS liposomes. Portes et al. (2015) by SEM reported unusual changes in tachyzoites shape after inhibition of Toxoplasma antioxidant enzmes by a dinuclear iron (III) compound. Hongfei et al. (2018) by SEM found decreased tachyzoites size with surface depressions after Licochalcone A treatment.

In the present study, biochemical analysis revealed the lowest serum level of AST \& ALT in group treated with target combination with mean number of $(281,29.4)$ respectively and a highly significant difference with other groups in acute toxoplasmosis. In chronic phase, the levels of ALT \& AST returned to normal levels. This agreed with Iribhogbe et al. (2017) who evaluated safety of artemisinin-based combinations for uncomplicated Plasmodium falciparum treatment in the $2^{\text {nd }} \& 3^{\text {rd }}$ trimester of pregnancy and found no significant change $(\mathrm{p}>0.05)$ in ALT \& AST levels

\section{Conclusion}

The combination between artesunate loaded nanofiber and spiramycin proved to have a strong effect against $T$. gondii tachyzoites during the acute phase and brain tissue cyst in chronic one. The capacity of target drug combination to cross the blood-brain barrier gave a promising result for acute and chronic toxoplasmosis with marvelous effect and mild toxicity.

Authors' contributions: Enas F. Abdel-Hamed, Nahed E. Mostafa, conceived designed the experiments, shared practical part and wrote manuscript. Amira A. Sale, Marwa A. Salama and Shereen M. Ibrahim shared practical part, analysis, contributed agents/mat- 
erials analysis tools and revised manuscript, Said M. Ahmed loaded nanodrug and characterized it. Hayam E. Rashed did histopathological study.

Conflict of interest: The authors declared that they neither have conflict of interest nor received financial support

\section{References}

Abou-El-Naga, FI, El-Kerdany, DE, Mady, F R, Shalaby, IT, Zaytoun, ME, 2017: The effect of lopinavir/ritonavir and lopinavir/ritonavir loaded PLGA nanoparticles on experimental toxoplasmosis. Parasitol. Int. 66, 6:735-47.

Antczak, M, Dzitko, K, Długońska, H, 2016: Human toxoplasmosis-searching for novel chemotherapeutics. Biomed. Pharmacother. 82: their high toxicity and severe adverse 677 84.

Barakat, AM, 2007: Some diagnostic studies on male New Zealand rabbit experimentally infected with Toxoplasma gondii strain. Glob. Vet. 1, 1:17-23.

Barradell, LB, Fitton, A, 1995: Artesunate: a review of its pharmacology and therapeutic efficacy in treatment of malaria. Drugs 40:714-41.

Chan, JM, Valencia, PM, Zhang, L, Langer, R, Farokhzad, OC, 2010: Polymeric nanoparticles for drug delivery. Meth. Mol. Biol. 624: 163-75.

Daryani, A, Hosseini, AZ, Dalimi, A, 2003: Immune responses against excreted/secreted antigens of Toxoplasma gondii tachyzoites in the murine model. Vet. Parasitol. 113:123-34.

El Zawawy, LA, 2008: Effect of artesunate on Toxoplasma gondii: In vitro \& in vivo studies. J. Egypt. Soc. Parasitol. 38, 1:185-201.

El-Temsahy, MM, El-Kerdany, ED, Abou-Shama, LM, 2002: Study of the role of antioxidant in experimental toxoplasmosis. J. Med. Res. Inst. 23, 3:59-69.

El-Zawawy, AL, El-Said, D, Mossallam, FS, Ramadan, SH, Younis, SS, 2015b: Triclosan and triclosan-loaded liposomal nanoparticles in the treatment of acute experimental toxoplasmosis. Exp. Parasitol. 149:54-64.

El-Zawawy, LA, El-Said, D, Mossallam, SF, Ramadan, HS, Younis, SS, 2015a: Preventive prospective of triclosan and triclosanlinposomal nanoparticles against experimental infection with a cystogenic ME49 strain of Toxoplasma gondii. Acta Trop. 141:103-11.

Engel, G, Farid, N, Faul, M, Richardson, L,
Winneroski, L, 2000: Salt form selection and characterization of LY333531mesylate monohydrate. Int. J. Pharm. 198:239-47

Gomes, TH, De Andrade, HFJ, Lescano, SA, Amato-Neto, V, 2012: In vitro action of antiparasitic drugs, especially artesunate, against $T o$ xoplasma gondii. Rev. Soc. Bras. Med.Trop.45, 4:485-90.

González-del, CM, Mondragón, M, González, S, Mondragón, R, 2009: Induction and regulation of conoid extrusion in Toxoplasma gondii. Cell. Microbiol. 11, 6:967-82

Gutiérrez, V, Seabra, AB, Reguera, RM, Khandare, J, Calderón, M, 2016: New approaches from nanomedicine for treating leishmani-asis. Chem. Soc. Rev. 45, 1:152-68.

Holfels, E, McCauley, J, Mack, D, Milhous, WK, McLeod, R, 1994: In vitro effects of artemisinin ether, cycloguanil, hydrochloride (alone and in combination of sulfadiazine), quinine sulfate, mefloquine, primaquine phosphate, trifluoperazine hydrochloride, and verapamil on Toxoplasma gondii. Antimicrob. Agents Chemother. 38:1392-6.

Hongfei, SI, Chunyan, XU, Zhang, J, Xukun, Z, Bing, Li, et al, 2018: Licochalcone A: An effective and low-toxicity compound against Toxoplasma gondii in vitro and in vivo: Drugs \& drug resistance. Int. J. Parasitol. 8, 2:238-45.

Iribhogbe, O I, Emmanuel, I, Odianosen, M, 2017: Comparative analysis of the safety and to lerability of fixed-dose artesunate/ amodiaquine versus artemether/lumefantrine combinations for uncomplicated falciparum malaria in pregnancy: A randomized open label study. Clin. Pharmacol. 9:45-54.

Jiao, YJ, Yang, QY, Liu, JM, Li, GJ, Yi, C, et al, 2018: Artemisinin and Artemisia апnиa leaves alleviate Eimeria tenella infection by facilitating apoptosis of host cells and suppressing inflammatory response. Vet. Parasitol. 254, 30: 172-7.

Kenry, L, Chwee, T, 2017: Beyond the current state of the syntheses and applications of nanofiber technology. Progr. Polymer Sci. 70, 17:16.

Khalil, NM, de Mattos, AC, Carraro, TC, Ludwig, DB, Mainardes, RM, 2013: Nanotechnological strategies for the treatment of neglecteddiseases. Curr. Pharm. Des. 19, 41: 7316-29.

Kirkwood, BR, 2003: Essential Medical Statistics. Blackwell Science, Inc.,

Loo, CSN, Lam, NSK, Yu, D, Su, X, Lu, F, 
2017: Artemisinin and its derivatives in treating protozoan infections beyond malaria. Pharmacol. Res. 37:192-217.

Ma, G, Liu, Y, Peng, C, Fang, D, He, B, et al, 2011: Paclitaxel loaded electrospun porous nanofibers as mat potential application for chemotherapy against prostate cancer. Carbohydr. Polym. 86, 2:505-12.

Martins-Duarte, ÉS, De Souza, W, Vommaro, RC, 2013: Toxoplasma gondii: The effect of fluconazole combined with sulfadiazine and pyrimethamine against acute toxoplasmosis in murine model. Exp. Parasitol 133, 3:294-9.

Martins-Duarte, ES, Lemgruber, L, De Souza, W, Vommaro, RC, 2010: Toxoplasma gondii: Fluconazole and traconazole activity against toxoplasmosis in a murine model. Exp. Parasitol. 124, 4:f466-9.

McLeod, R, Van Tubbergen, C, Montoya, J G, Petersen, E, 2014: Human Toxoplasma Infection. Second Edition. Elsevier.

Meneceur, P, Bouldouyre, MA, Aubert, D, Villena, I, Menotti, J, et al, 2008: In vitro susceptibility of various genotypic strains of Toxoplasma gondii to pyrimethamine, sulfadiazine, \& atovaquone. Antimicrob. Agents Chemother. 52, 4:1269-77.

Mesa, EL, Lutgen, P, Velez, DI, Segura, MA, Robledo, MS, 2015: Artemisia annua L., potential source of molecules with pharmacological activity in human diseases. Am. J. Phytomed. Clin. Therapeut. 3, 05:436-50.

Ou-Yang, K, Krug, EC, Marr, JJ, Berens, R L, 1990: Inhibition of growth of Toxoplasma gondii by qinghaosu and derivatives. Anti-microb. Agents Chemother. 34:1961-5.

Pappas, G, Roussos, N, Falagas, M, 2009: Toxoplasmosis snapshots: Global status of Toxoplasma gondii seroprevalence and implications for pregnancy and congenital toxoplasmosis. Int. J. Parasitol. 39:1385-94.

Penido, MLO, Nelson, DL, Vieira, LQ, Coelho, PMZ, 1994: Schistosomal activity of alkyl aminooctane thiosulfuric acids. Mem. Inst. Oswaldo Cruz 89, 4:595-602.

Peters, PJ, Thigpen, MC, Parise, ME, Newman, RD, 2007: Safety and toxicity of sulfadoxine /pyrimethamine implications for malaria preven- tion in pregnancy using intermittent preventive treatment. Drug Saf. 30:481-501.

Portes, JA, Souza, TG, dos Santos, TA, da SiIva, LR, Ribeiro, TP, et al, 2015: Reduction of Toxoplasma gondii development due to inhibition of parasite antioxidant enzymes by a dinuclear iron(iii) compound. Antimicrob Agents Chemother. 59, 12:7374-86.

Ramakrishna, S, Teo, W, Lim, T, et al, 2005: An introduction to electrospinning and nanofibers. Singapore: Wld. Scientific. https: // doi.org/ 10.1142/5894

Robert-Gangneux, F, Dardé, ML, 2012: Epidemiology of and diagnostic strategies for toxoplasmosis. Clin. Microbiol. Rev. 25, 2:264-96.

Scallan, E, Hoekstra, RM, Angulo, FJ, Tauxe, RV, Widdowson, MA, et al, 2011: Foodborne illness acquired in the United States-major pathogens. Emerg. Infect. Dis. 17: 7-15.

Seeram, R, Zamani, M, Molamma, PP, 2013: Advances in drug delivery via electrospun and electrosprayed nanomaterials. Int. J. Nanomed. 29:97-9.

Shenoy, SL, Bates, WD, Frisch, HL, Wnek, G E, 2005: Role of chain entanglements on fiber formation during electrospinning of polymer solutions: Good solvent, non-specific polymer/ polymer interaction limit. Polymer 46:3372-84.

Shubar, HM, Lachenmaier, S, Heimesaat, M, Lohman, U, Mauludin, R, et al, 2011: SDS coated atovaquone nanosuspensions show improved therapeutic efficacy against experimental acquired and reactivated toxoplasmosis by improving passage of gastrointestinal and blood-brain barriers. J. Drug Target 19, 2:114-24.

Tamer, U, Flemming, B, 2009: Electrospinning of cyclodextrin functionalized polyethylene oxide (PEO) nanofibers. J. Euro. Polymer 45: 1032-7.

Thakkar, $\underline{S}$, Misra, $\underline{M}, 2017$ : Electrospun polymeric nanofibers: New horizons in drug delivery. Euro. J. Pharm. Sci. 107, 30:148-67.

Wang, ZD, Wang, SC, Liu, HH, Ma, HY, et al, 2017: Prevalence and burden of Toxoplasma gondii infection in HIV-infected people: A systematic review and meta-analysis. Lancet 4:4. Weiss, L, Kim, K, 2014: Toxoplasma gondii: The model Apicomplexan Perspectives and Methods, Second Edition. Elsevier Inc.

\section{Explanation of Figures}

Fig. 1: Sections in cerebral tissue of chronic T. gondii control and treated mice (H\&E x400) showing (a) brain in control healthy mice with astrocytes (black arrow), and neurons (red arrow). (b) infected control mice with cyst formation in brain (arrow). (c) brain of infected mice treated by spiramycin with moderate inflammatory infiltrate and presence of cysts (arrows). (d) infected mice treated by artesunate with moderate inflammatory infiltrate and brain cysts (arrow). (e) infected mice treated by artesunate loaded nanofiber with mild inflammatory 
infiltrate and distorted cyst in brain (arrow). (f) brain of infected mice treated by spiramycin and artesunate with increased gliosis and astrocytosis and few inflammatory cells (arrows). (g) infected mice and treated by spiramycin \& artesunate loaded nanofiber where brain regained normal architecture confirmed by increased astrocytes, neurons, and gliosis without $T$. gondii cyst (arrows).

Fig. 2: SEM of T. gondii tachyzoites and tissue cysts of infected non-treated and infected treated mice: (A) Normal crescent-shaped and smooth surfaces of tachyzoites in infected not treated, (B) Distorted crescent shapes of tachyzoites showing irregular surface and reduction in size with abnormal protrusions in surface outline in mice treated with target drug combination. (C) Normal oval shape and size of brain cysts. (D) An abnormal small sized cysts in brain with distorted shape, patches all over with irregular surface in mice treated with target drug combination.
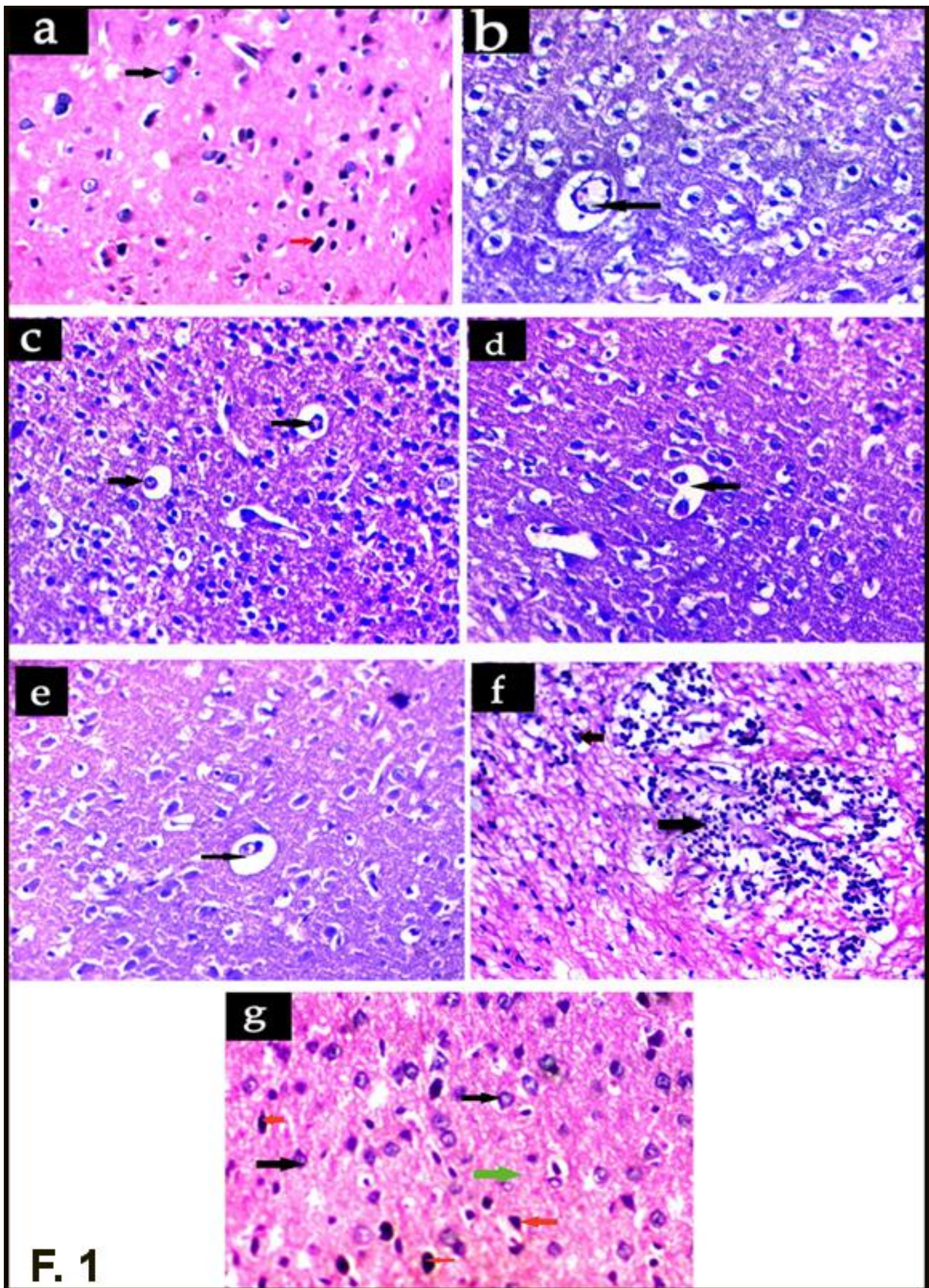


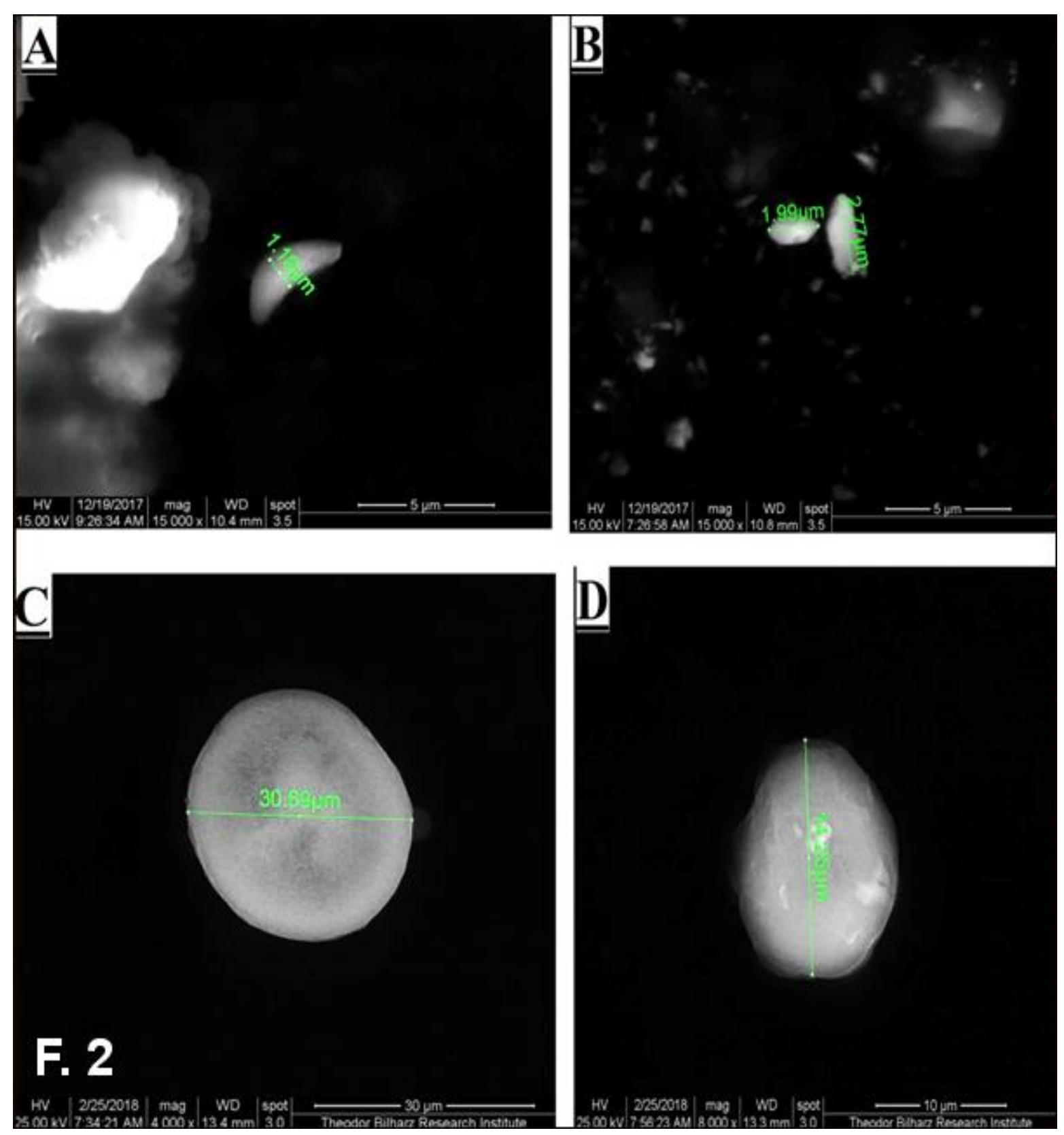

